\title{
INTERNATIONAL DEMAND AND MOTIVES FOR AFRICAN COMMUNITY-BASED TOURISM
}

\author{
Noel Biseko LWOGA* \\ Department of Archaeology and Heritage Studies, University of Dar es Salaam (Tanzania) and School \\ of Tourism \& Hospitality, University of Johannesburg (South Africa), e-mail: noelight79@gmail.com
}

Citation: Lwoga N.B., (2019). INTERNATIONAL DEMAND AND MOTIVES FOR AFRICAN COMMUNITY-BASED TOURISM, GeoJournal of Tourism and Geosites, 25(2), 408-428. https://doi.org/10.30892/gtg.25212-370

\begin{abstract}
This study utilizes the push-pull model to understand demand for community-based tourism (CBT) in sub-Saharan Africa (SSA). Data was collected through an online Google Form survey undertaken with respondents in Eberswalde, Germany. The findings show that there is a substantial international demand for CBT. The push motives behind the demand are not only limited to interaction, novelty seeking, authentic and new knowledge and sharing economy ethos, but also include physical motives of relaxation. This is in contrast to a dominant argument that motives for CBT represent the dichotomous polarized discourses of soft versus hard with reference to the notions of interaction versus relaxation. The findings also show that the mere presence of natural and cultural resources does not structure pull motives, but critical in pulling tourists are the traditional use of the resources by the local community, safety and security, accessibility, quality of service and sustainability aspects of CBTs. In addition, the findings indicate that potential tourists prefer to arrange CBT tour themselves through the internet and website. The implications of these findings are examined for conceptualizing tourism demand and motives and marketing of CBT in SSA.
\end{abstract}

Key words: Community-based tourism; Sub-Saharan Africa; international tourism demand; tourist motivation

\section{INTRODUCTION}

The region of Sub-Saharan Africa (SSA) has recorded a decline in rates of poverty from $56 \%$ in 1990 to $43 \%$ by 2012 (World Bank, 2017). The region's economic growth is expected to rise to 3.6 percent in 2020 from 2.3 percent in 2017 (World Bank, 2019). Tourism is among the key industries which are driving change in SSA. From a small base of 6.7 million visitors in 1990, the region attracted 33.8 million tourists in 2012 generating over USD 36 billion and 2.8\% of GDP in the region (World Travel and Tourism Council (WTTC), 2013). In 2017 tourism's direct contribution to GDP was USD 43.7 billion or about 2.7 of total GDP (WTTC, 2018). Attractions that draw international

\footnotetext{
* Corresponding author
} 
tourists to SSA have mainly been nature-based to iconic state-controlled national parks and game and forest reserves. This said, tourism's potential to enhance poverty alleviation in the region depends on tourist direct visits and spending in local communities.

Community-based tourism (CBT) is a form of tourism that involves tourists visiting and experiencing local community's cultural and natural heritage resources, where the community has a substantial control over, and involvement in their development and management, and where a major proportion of the benefits remain within the community (Rozemeijer, 2001). CBT provides to urban or (more commonly) rural disadvantaged communities opportunities for new income opportunities to complement traditional livelihoods, including for selling local products (Rozemeijer, 2001; World Tourism Organization, 2002; Rogerson, 2006, 2007; Teh \& Cabanban, 2007; López-Guzmán et al., 2011; Stone \& Rogerson, 2011; Croes, 2014; Reggers et al., 2016; Wang et al., 2016; Thompson et al., 2016; Dodds et al., 2018). Although CBT is not a panacea for all rural impoverished areas, under certain circumstances it can contribute both to economic diversification and the consolidation of small-scale traditional livelihoods by providing complementary revenue (Manyara \& Jones, 2007; Zapata et al., 2011).

Consequently, many developing countries currently promote it as an alternative form of tourism development which is intended to counter unsustainable practices of conventional mass tourism to nature-based attractions, and as an inclusive type of tourism that, in contrast to state or privately-owned designated sites promotes community ownership and development (Rozemeijer, 2001; Hall, 2010; Mgonja et al., 2015; Mtapuri et al., 2015; Atanga, 2019; Strydom et al., 2019).

Despite the promising benefits of CBT initiatives, several academic studies and industry reports indicate that their economic performance is relatively poor (Goodwin \& Santilli, 2009; Stone \& Rogerson, 2011). Most CBT initiatives are observed to have a low economic impact on poverty alleviation as compared to the effects of mainstream tourism or other alternative economic activities (Mitchell \& Muckosy, 2008). In addition, many initiatives are short-lived due to a failure to self-sustain financially especially after external funding from donors and NGOs ends (Sebele, 2010; Salazar, 2011; Zapata et al., 2011; Mgonja et al., 2015). Existing studies attribute CBT failures to several factors which include limited funding, inadequate infrastructure as well as know-how necessary for planning, implementing and monitoring business-oriented activities, unfavorable remote locations, and limited connection to mainstream tourism enterprises and existing tourism supply chains (EplerWood, 1998; Akunaay et al., 2003; Nyaupane et al., 2006; Anderson, 2015; Mgonja et al., 2015). In addition, its benefits often are co-opted and monopolized by elites as a result of exclusion of the poor/have nots from CBT structures (Mowforth \& Munt, 2003). In addition, from the point of view of CBT business, a core factor underpinning CBT problems in SSA - and the concern of this study - is their inability to attract adequate number of tourists for sustainable operations (Goodwin \& Santilli, 2009; Mtapuri et al., 2015; Lubbe et al., 2016; Atanga, 2019). In SSA CBTs depend highly on international tourists, especially from Europe, to generate profits and financial contributions to the local economy (Mitchell \& Ashley, 2007; Rogerson, 2007; Kayat, 2014). In some research it is reported almost 50\% of mainstream European tourists express an increased interest in CBT products (CBI, 2015) but CBT initiatives still receive a relatively limited number of these international tourists. Beyond their failure to attract tourists from their source markets, CBT initiatives often fail even to capture adequate market share from tourists visiting state and private-controlled national parks and reserves in their vicinity. For example, in Tanzania, while state-controlled parks and reserves receive more than one million tourists annually, CBT initiatives located in villages around the parks receive only about 30,000 tourists (URT, 2017). Arguably, CBT initiatives in SSA hold 
limited marketing information and skills necessary to attract and satisfy international tourists (Goodwin \& Santilli, 2009; Anderson, 2015 Mgonja et al., 2015).

In most cases, they depend on either intermediaries such as responsible tour operators or support from NGOs to carry out the marketing function (Lwoga \& Asubisye, 2016). For sustainable CBT initiatives in SSA an improved knowledge about international market demand, especially of tourist motivations for CBT products is warranted.

Pull-push motivation theory places motivations to visit tourism products into the categories of push and pull. Push factors include socio-psychological motives and forces in people's lives that generate the desire to travel and visit places (Klenosky et al., 2007; Sing'ambi \& Lwoga, 2018). Pull factors include destination/product-generated forces that attract people to select one destination/product over another once the decision to travel has been made (Klenosky et al., 2007). The extant knowledge regarding motivations to visit CBT products, based on pull-push theory, is criticized to have emerged mostly from other regions than SSA, and from examination of CBT tourists during their actual visits and post-visits rather than pre-visits. It thus overlooks the demand insights from SSA perspective, and from the pre-visit tourists in their originating region. It is well-known that differences exist in cultures, tourism economies, history, geopolitics, social and demographics between SSA and other world regions that influence the way foreign tourists perceive SSA tourism products (Timothy \& Nyaupane, 2009).

In particular, it is not clear whether potential international tourists to SSA - a region well-known for nature-based tourism - have CBTs as a preferred attraction in their minds, and how this would happen, before actual visits. This knowledge is vital for the development and marketing of CBT products and for their financial sustainability.

Understanding the SSA CBT market from the perspective of potential international tourists during pre-visit may lead to widening insight into demand, and thus, the estimation of the potential marketability of CBTs. This exploratory study based on push-pull theory examines potential German tourists, mostly from Eberswalde, a university town near the German capital (Berlin), and seeks to address a range of issues surrounding potential demand for SSA CBT. The study specifically intends to answer the following questions: Are Europeans (specifically Germans) interested in choosing SSA CBTs as part of their holiday experiences? What factors motivate them to consider CBTs? What are means through which they receive information about SSA CBT? How would they wish to arrange their travel to SSA CBT destinations? An exploration of the demand for SSA CBTs during pre-visits - when their views are limitedly intertwined with on-travel experiences - allows for a broader understanding of tourists' choice to visit CBTs. In addition, it provides critical inputs to CBT coordinators and practitioners to determine appropriate CBT product development and marketing strategies.

\section{THEORETICAL FRAMEWORK Community-based Tourism}

Since the 1970s two significant changes are observable concerning the tastes of tourists and a new direction in tourism development agendas to support the inclusion of local communities. On the one hand, tourist tastes moved towards experiences (apart from mass tourism) and in destinations with a greater focus on local customs, history, ethics, ecotourism and environmental-friendly activities (López-Guzmán et al., 2011).

On the other hand, tourism linked to a community's inherent cultural and natural resources and to active participation of local communities became key influences in fostering the upliftment of such communities (López-Guzmán et al., 2011). An increased interest in community heritage and culture, as well as ownership, participation and management of tourism activities by local communities shaped the concept of 
community-based tourism (CBT) (Murphy, 1985; Rozemeijer, 2001; Mtapuri et al., 2015). It is argued that the concept of CBT emerged as part of counter-cultural responses and sustainable alternative to mass/mainstream tourism and its negative impacts upon the environment and the socio-cultural aspects of destination communities (Goodwin \& Santilli, 2009). CBT is one among several types of alternative tourism that are considered to have potential for achieving the goals of sustainable tourism and development (Atanga, 2019). Most alternative kinds of tourism, including ecotourism, place the natural environment and its conservation as the core subject of their developments with their operations often favoring elite business and state interests. By contrast, CBT is an approach that focuses on the community dimension of tourism with the hope of placing the needs and capabilities of communities at the forefront of tourism development (e.g. Heenan, 1978). Since its emergence in early tourism works of the 1970s, many scholars, activists and practitioners have attempted to define CBT (Strydom et al., 2019).

Goodwin \& Santilli (2009) broadly define it as tourism that is owned and/or managed by communities and intended to deliver wider community benefits. Lapeyre (2010) views it as an activity which, through increased intensities of participation, provides widespread economic and other benefits and decision-making power to communities, and advocates capacity building and empowerment. Zapata et al. (2011) consider it as any business organizational form grounded on the property and selfmanagement of the community's patrimonial assets, according to democratic and solidarity practices; and on the distribution of the benefits generated by the supply of tourist services, with the aim at supporting intercultural quality meetings with the visitors.

Overall, several features define CBT (Strydom et al., 2019). These include location, participation, equitable distribution of benefits, empowerment and ownership, and activities. In terms of location, scholars agree that CBT takes place and utilises resources, mainly people's way of life, culture and nature - conventionally - within a small rural community, but today extends also into urban settings. In terms of participation, CBT management is done by community members who can influence the decision-making, development and monitoring processes. Regarding the equitable distribution of social and economic benefits, local communities capture most revenue generated on site and maximise linkages for the local economy. Collective benefits are provided through contributions to community funds for the development of community assets such as schools, clinics, grinding mills, water wells, and through the creation of opportunities such as paid employment in the CBT enterprises, micro-enterprise sales and purchases from local industries. In terms of empowerment and ownership, since local inhabitants fully and actively participate in the management of CBT, the community members gain institutional and managerial capacity, and a sense of ownership of tourism. Although what constitutes an acceptable balance between individual initiatives and community benefits is contested, the importance of ownership and/or management by communities for empowerment is viewed as significant (Kontogeorgopoulos et al., 2014).

Conventionally, most CBT activities focus on nature conservation through an ecotourism product in rural context; more recently, it involves a broader range of products such as rural and urban local culture and folklore, lodges or homestays, walking trails to community heritage assets, local restaurants, interpretation center, souvenir shops, local museum and cultural centers, camping sites, as well as local guiding and traditional transport service/attraction (Goodwin \& Santilli, 2009; Zapata et al., 2011). These activities and products are organized differently, ranging from a purely communitarian co-operative (village tourism) to several community enterprise group or NGOs, to more conventional destination, public and business management models. (Zapata et al., 2011). Hitchins \& Highstead (2005) caution that structure of CBT often 
subscribes to some forms of charity, thereby depending on donors and fail to survive as independent entities in the long-term. However, because its core function in tourism as a commercial business rather than a charity function, CBT's structure needs to build a sustainable enterprise that is self-sufficient (Hitchins \& Highstead, 2005).

In most cases, the CBT structures which succeed in ensuring economic sustainability, apart from being in prime areas and well connected to the private sector, are marketing-oriented in their function (Hitchins \& Highstead, 2005). Thus, understanding CBT market is critical to the structuring of a successful CBT entity.

\section{Tourists' Choice of Tourism Products: Push-Pull Theory}

The quest for understanding the choice of a tourism product falls within the domain of tourism marketing theories, and specifically, motivation, consumer or tourist behavior theories. The theory of push and pull is the most dominant (Klenosky et al., 2007). Push-pull theory posits that individuals visit places because they are pushed by internal desire and pulled by external forces (Crompton, 1979; Klenosky et al., 2007). The importance of the theory is inherent in its push and pull dimensions that represent the two major segments of the tourism system, that is, the demand and supply. Regarding this, the theory has been useful in directing tourism managers that, individual tourists have control over their decision to visit places, and it is up to the managers to address the motivation benefits sought of tourists (Sing'ambi \& Lwoga, 2018). Push factors refer to motivations including individual internal and psychological forces that cause or push them to visit places outside their usual environment (Klenosky et al., 2007).

They are specifically a set of needs that cause a person to engage in a tourism activity, and in most cases, occur because of cultural and socio-psychological disequilibrium that a person feels, and requires a travel experience to be corrected (Park \& Yoon, 2009). Regarding this, the push factors or motivations often are intangible and tourist-origin oriented (Park \& Yoon, 2009). Maslow's hierarchy of needs, which puts human needs into the categories of physiological, safety, social, esteem and selfactualization, posits that the next need appears once the lower need is satisfied (IsoAhola, 1982). This means that a person's decision to visit a place is associated with her/his requirements, and adjusted according to the need that has to be fulfilled. Although the hierarchy of needs has been criticized, the category of needs such as the need for recognition, self-esteem and self-actualization, provides insights into the push factors.

Most existing empirical studies which investigate tourist motivations focus on general or specific kinds of tourism rather than specifically on community-based tourism products. Goeldner \& Ritchie (2006) differentiate four categories of tourist motivation, namely physical such as relaxation, cultural such as discovering new geographical areas, interpersonal such as socializing and meeting new people, and prestige such as selfesteem and self-actualization. Pearce \& Lee (2005) argue that escape from a perceived mundane environment, relaxation, relationship enhancement and self-development are central motivations for all types of tourists. Jang \& Wu (2006) revealed that knowledgeseeking, relaxation and family togetherness are significant motivations. The limited studies that address CBT related products have found similar motivations. For example one report on European tourist's expectations and demands for CBT argues that CBT tourists' motives can be put into two polar categories (CBI, 2015). These are hard CBT tourists who seek deep, genuine cultural experiences and the authenticity of community life and soft CBT tourists who seek interaction with local communities but with some levels of comfort. Nevertheless, with reference to tourists visiting rural tourism villages in Korea, Park \& Yoon (2009) found that relaxation represents a central distinguishing motivational theme, followed by interaction, learning, family togetherness, novelty and excitement. Guttentag et al. (2018) examine tourists' choice to reserve and stay in local 
rural residences in Europe and America through Airbnb and disclosed interaction is a central motivation, followed by home benefits (staying in a home-like environment), novelty, sharing economy ethos (contributing to local communities economically and environmentally) and local authenticity (need to have an authentic local experience in a non-touristy neighborhood). Agyeiwaah (2013) focused on international tourists' motivation for choosing homestay in Ghana, and found the following motivations as important: (i) socio-cultural motives such as interaction with local folks, making new friends in Ghanaian community, enjoying authentic local experience, self-development and relaxation, speaking Ghanaian language, cooking Ghanaian foods, enjoying a sense of home, understanding local lifestyle and experiencing Ghanaian religious life, and (ii) educational motivations such as learning new things from local communities and serving in local schools. According to Agyeiwaah (2013) the interaction with local people was the most important motivational attribute for international tourists' choices of homestay in Ghana. Overall a debate still exists on whether push motives are limited to either hard or soft categories or a plurality of motives, including whether relaxation or interaction is the most important factor. Pull factors refer to destination-generated forces that attract individuals and influence them to select one destination over another once the decision to travel has been made (Klenosky et al., 2007; Sing'ambi \& Lwoga, 2018). They are the functions of the tourism product supply that stimulate tourists to choose it (Hsu \& Lin, 2011). These include destination attributes such as its natural and cultural attractions, infrastructure that translate into access, service dimensions such as accessibility, cost, safety, quality, social facilities, sanitation and comfort, and the extent the image of a destination is promoted (Jang \& Wu, 2006; Isa \& Ramli, 2014). Destination attractions are considered key constituents in pull factors because they translate into activities that tourists can be engaged in and build the image of the destination (Sing'ambi \& Lwoga, 2018). In fact, activities are considered as central to understanding the tourism decision-making process because they not only translate directly to action or behaviour but can also be treated as the outcome of tourist preferences (Mumuni \& Mansour, 2014). This means that, with its inherent association with attraction, tourism activity forms an important criterion that affects tourist's choice of a destination. In general, the kinds of tourism activities that can pull tourists to visit a place can be put into various categories. These include visiting historic/cultural sites, challenging nature-based activities, relaxing nature-based activities and pleasure-based activities (Mehmetoglu, 2007). Choi \& Tsang (2000) offer a different categorization scheme, that is, sightseeing activities; outdoor sport activities, entertainment activities, and friends/relatives visiting activities from activity items. In addition, Madrigal \& Kahle (1994) consider visits to ancestral homelands as another tourism activity. Studies that have focused on rural destination environment - albeit not necessarily on CBT - find that while nature and scenery for passive tourist gaze or more physically demanding outdoor activities are dominant pull factors (Kline et al., 2014), rural culture and way of life form a minority or secondary interest (Sidali \& Schulz, 2010). The rural culture and way of life is, however, popular as an attraction to special-interest tourists such as those interested in local wine and foods, specific outdoor sports and wellness pursuits (Sidali \& Schulz, 2010; Kline et al., 2014; Perkins et al., 2015). In the case of South Korea, agriculture, cultural and historical elements in the countryside are important attractions to a number of rural tourists (Park et al., 2004). In rural South Carolina, USA Huang et al. (2016) found that nature-based and less-adventurous sports-related activities, heritage sites, local souvenirs, local foods and festivals were popular pull factors.

Based upon research in rural Portugal using an activity-based approach Eusébio et al., (2017) revealed that visitors were mostly motivated by - in rank order - resting, appreciating the landscape, contact with nature, cultural enrichment (visiting historical 
villages), tasting local gastronomy, visiting monuments, visiting friends and relatives, and interacting with local people. The following activities were least referred to when visiting the countryside: participating in traditional local economic activities, going on thematic tours (e.g. wine, chestnut and blueberry tours) and fishing (Eusébio et al., 2017).

According to Eusébio et al. (2017) these results suggest four categories of tourists based on activity-attributes. These include (i) active visitors who undertake a wide range of activities and mostly in nature-related activities such as observing local fauna and flora, appreciating the beauty of the landscape, and in cultural activities such as visiting museums, monuments and historic villages, tasting local cuisine as well as interact more than others with local residents; (ii) Passive nature observers who explore the countryside in a relatively superficial manner, as they undertake a limited number of activities, mainly landscape observation, contacting with nature and resting; (iii) Inactives who engage in few activities mainly resting and visiting friends and relatives; and (iv) Summer Family Vacationers who have a higher tendency to interact with locals in a VFR context, to go to the beach, contact with typical local products and economic activities (e.g. tasting local cuisine, wines and agricultural products, buying local crafts and visiting historical and traditional villages). Other research studies on tourist motivation find that visiting friends and relatives (VFR) attracts tourists are nostalgically interested in revisiting rural places where their family roots lie (Pesonen, 2012; Rodrigues et al., 2012; Rogerson, 2018; Rogerson \& Rogerson, 2019). Germany (the focus of this study) historically colonized parts of SSA including Togoland (now part of Ghana and Togo), Cameroon, German East Africa (now Rwanda, Burundi and Tanzania) and German South-West Africa (now Namibia). Consequently, as a result of the colonial record there are many places in Africa with German colonial heritage and offer opportunities that their existing heritage assets and history might attract certain Germans to visit African destinations for curiosity about their history. Overall, in terms of the tourism market of Germany the enjoyment of natural scenery was disclosed as the leading factor in choice of a place to visit in surveys undertaken in 2007/2008 and again in 2015/16 (German Consumer and Travel Trade Research, 2008 - in Koppalova 2014). According to ADAC Reise-Monitor (2016) the motivations of most German tourists are to experience beautiful scenery (58\%), sunshine and nice weather (57\%) and bathing/swimming (46\%), followed by culture including experiencing the local life (47\%) and getting to know other countries and cultures (40\%) as the most important reasons to go on holiday. The findings reported by the German Consumer and Travel Trade Research of 2008 show also that experiencing local culture and interacting with the local people, and visiting historic sites, museums and galleries as among important reasons for Germans to go on holiday. This said limited research has examined specific motives for Germans to visit CBT products in SSA.

Beyond tourism activities, another important key component of pull factors is service. Regarding service dimension, Hsu \& Lin (2011), in a study of CBT product homestay motivation in Taiwan, found that quality, prices, sanitation and comfort, transportation and social demands and facilities were important pull factors in tourist's selection of homestay. Wang (2007)'s research on Naxi homestays in China found the destination activity attribute of Naxi culture and lifestyle to be the primary motivation for guests' choice of homestay. Other relevant factors include service attributes such as price, comfort/convenience in the houses and local architecture. Agyeiwaah (2013) found that tourist's considerations that homestay as a way of giving back to locals, as a product that offers lower prices and value for money, and promotes community development were the most important pull factors in her/his choice of homestay in Ghana, followed by tourist's considerations of homestay as secured form of accommodation offering comfortable and convenient quality service (security and comfort), and homestay as promoter of 
environmental preservation (environmental factors). In addition, it has been shown that European CBT tourists consider health and safety, authentic accommodation, ecofriendly and social responsibility sustainability features and internet access among key service factors that would pull them to a particular CBT place (CBI, 2015). Mtapuri et al.'s (2015) Visitor Affinity Index (showing tourists' expectations for CBT) indicates that quality of visitor access and infrastructure (e.g. road and water), facilities (e.g. toilet, shower and bath, accommodation), quality versus price value, cleanness and hygiene, and general safety and security as important service elements. What emerges from a literature search is that while relaxation and nature seem to be fundamental push and pull factors in international tourists' choice of visiting tourism places in general, for CBT products issues of interaction and rural culture seem important push and pull factors. In addition, consideration of CBT as a way of giving back to community, and concerns over security and safety are also key in tourists' choice of CBT. This conclusion needs to be considered with caution as most existing scholarship relates only to a single unit of a CBT product that relates to accommodation (ie the homestay) whereas as discussed earlier a tourist consumes diverse array of product lines when visiting CBT places. Further, with the exception of Agyeiwaah (2013), most studies focus on contexts other than SSA. Of note also is that few studies examine tourist motivations at the pre-visit stage. This gap in knowledge limits the holistic understanding of CBT demand given that the nature of the tourism supply, economic, cultural and geographical settings, as well as images, and thus the set-up of CBT products, differ between sites in the developed world and in SSA, and the tourist motivations differ between pre-visits and on-visit stages due to on-travel influences.

\section{METHODOLOGY}

\section{Research Design and Study Area}

The study is part of a wider research undertaking that intends to explore and examine the market for CBT in sub-Sahara Africa This paper is an exploratory case study drawing on the German market. The study was basically an exploratory crosssectional research which was guided by critical realism and its ontomological and epistemological underpinnings for mixed-method research (Creswell, 2003). With this philosophical direction, while objectivism was maintained, the complexity of the social phenomenon, that is, people's choices and the motives behind them, was recognized by enabling a role for values and interpretive meaning. The study applied mixed methods, combining close-ended and open-ended questions concurrently using a mixed survey instrument as articulated by Creswell (2003) and Tashakkori \& Teddlie (1998).

While the quantitative part of a mixed survey instrument with close-ended questions framed within the pre-conceived constructs from past research dominated, the qualitative open-ended questions aided the elicitation of qualitative and contextual information free from the conceptual boundaries. This helped the study to gain indepth insights that aided the interpretation of the quantitative data and revealed new issues regarding motives for choosing SSA CBTs. The study focused on residents of Eberswalde, a major town and administration centre of the Barnim District in Brandenburg State, 50 kilometers from Berlin. The deliberate selection of German market for research was guided by a number of reasons. First, German residents lead other European residents in terms of outbound travels, meaning that they have a high propensity to travel and spend abroad (CBI, 2015). Second, for sub-Saharan Africa, Germany is among top three tourist originating countries (see URT 2018). Three, it is established that Germans are increasingly interested in unique and authentic experiences such as engaging with the local community, and are ethically conscious tourists who consider the question of their contribution to local communities (CBI, 2015). 


\section{Sampling Procedures and Data Collection}

The target population were potential tourists to SSA in their country of origin, that is, people living around Eberswalde University of Sustainable Development. The sample size was 150 respondents. The study conducted random sampling inside and outside the premises of the Eberswalde University since relatively educated people are more likely to travel abroad. Respondents interested in participating in the study were informed about the aims of the study and the anonymity of their responses and were asked to provide their email addresses. A total of 121 persons answered the questionnaire. The respondents, as shown in Table 1, involved $60.3 \%$ female and $39.7 \%$ male. In terms of age range the largest share ranged between 18 and 29 years (48.8\%). In terms of occupation, the majority were university students (45.5\%), followed by university staff including administrators, academicians, researchers and scientists $(27.2 \%)$ and those engaging in private businesses (12.4\%). Respondents were well-educated as is shown on Table 1; the majority (88.4\%) had no children also reflecting that the sample is dominated by youth and students.

Table 1. Characteristics of respondents $(\mathrm{N}=121)$

\begin{tabular}{|c|c|c|}
\hline Variable & Frequency & \% \\
\hline \multicolumn{3}{|l|}{ Sex } \\
\hline Female & 73 & 60.3 \\
\hline Male & 48 & 39.7 \\
\hline \multicolumn{3}{|l|}{ Age } \\
\hline $18-29$ & 59 & 48.8 \\
\hline $30-49$ & 31 & 25.6 \\
\hline $50-64$ & 30 & 24.8 \\
\hline $65^{+}$ & 1 & 0.8 \\
\hline \multicolumn{3}{|l|}{ Education } \\
\hline Bachelor/ F-H Abschluss & 53 & 43.8 \\
\hline Master/ Universitatsabschluss & 49 & 40.5 \\
\hline Promotional/ PhD & 19 & 15.7 \\
\hline \multicolumn{3}{|l|}{ Number of Children } \\
\hline No Child & 107 & 88.4 \\
\hline 1 & 8 & 6.6 \\
\hline 2 & 6 & 5.0 \\
\hline \multicolumn{3}{|l|}{ Occupation } \\
\hline University Student & 55 & 45.5 \\
\hline University Administration & 16 & 13.2 \\
\hline Journalist & 3 & 2.5 \\
\hline Lecturer/Researcher/Scientist & 13 & 10.7 \\
\hline Professor & 4 & 3.3 \\
\hline Art Therapist & 3 & 2.5 \\
\hline Teacher & 5 & 4.1 \\
\hline Consultant/Travel or Tourism Agent & 7 & 5.8 \\
\hline Business & 15 & 12.4 \\
\hline \multicolumn{3}{|l|}{ Visited SSA Before? } \\
\hline No & 60 & 49.6 \\
\hline Yes & 61 & 50.4 \\
\hline
\end{tabular}

A mixed survey instrument was used to collect data including behavioral, opinion and attribute-based data. The instrument had both close and open-ended questions, prepared in English but with some German descriptions. The close-ended questions dominated the survey, and had scaled and categorical questions. The instrument was designed to start with the categorical question regarding choice of visiting SSA in general 
( $1=$ No, 2 = Maybe, $3=$ Yes), including countries of preference (nominal) and image of SSA tourism with eight items adopted from past research (Mtapuri, 2015) and anchored at the agreement scale ranging from $1=$ Strongly Disagree to $5=$ Strongly Agree.

It then continued with choice of SSA CBT in specific using variables such as wishes to participate in CBT when visiting SSA in future $(1=$ No, $2=$ Maybe, $3=$ Yes $)$. Regarding this, those who responded Yes were directed to respond to question regarding motives behind choice to participate in CBT when visiting SSA in future with ten items adopted from past research (Park \& Yoon, 2009; Agyeiwaah, 2013; Guttentag et al., 2017; Eusébio et al., 2017) and anchored at the importance scale ranging from $1=$ Not Important at All to 5 = Very Important. In addition, an open-ended question asking them to provide further motives behind their choice to visit SSA CBT was provided. On the other hand, those who responded either No or Maybe were subjected to an open-ended question asking them to provide reasons behind. The instrument also inquired about source of information about SSA CBTs and preferable travel arrangements to SSA CBT destinations using items borrowed from past research (CBI, 2015). The survey instrument was pretested before implementation using the survey tool (Google form web-based questionnaire) during November-December 2018. Data were exported from the websurvey tool (Google Form) to Excel and SPSS, and were cleaned, coded and checked for appropriateness. Since the study is exploratory in nature, exploratory and descriptive statistics such as mean and standard deviation statistics were used to analyse scaled quantitative data. Frequency and percentage tables were used to analyse categorical data, and thematic analysis was used to draw themes and meaning from qualitative statements.

\section{FINDINGS}

\section{Respondents' choice of SSA in general}

Descriptive statistics were employed to explore demand for SSA and specifically its CBT. Respondents were asked the question: "Do you wish to go on holiday in SSA?"; in total 72.7 percent of them responded "Yes" and 27.3 percent of them responded "Maybe" (Table 2). Respondents who answered "Yes" were asked to mention which country they wish to visit in SSA. As indicated in Table 3, the most preferable country destination is South Africa (20.7\%), followed by Namibia (12.5\%) and Tanzania (10.7\%).

The results indicate that countries in West Africa, with exception to Ghana, are less popular. Respondents were also asked to reveal their image of African tourism. The results indicated in Table 4 show overall that respondents hold a positive image about the SSA tourism product (overall mean $>3.5$ ). They specifically hold a good image of the SSA tourism product in terms of its authentic culture and unspoiled nature (mean > 3.5). By contrast, the findings indicate that respondents hold relatively poor image of SSA tourism product in terms of accessibility (mean = 3.02), easiness of obtaining touristic information (mean $=3.24$ ), and safety and security (mean $=3.23$ ).

\section{Respondents' choice of SSA's CBT}

In order to understand their demand for SSA's CBT in particular, respondents were asked "If given a chance to go on holiday in SSA, would you wish to participate in CBT and engage with local communities in their rural/urban setting as part of your holiday?". The affirmative findings are reported on Table 5 .

Table 2. Choice of destination in Sub-Sahara Africa

\begin{tabular}{|c|c|c|}
\hline & Frequency & Percent \\
\hline Wish to Visit SSA & & \\
\hline Maybe & 33 & 27.3 \\
\hline Yes & 88 & 72.7 \\
\hline Total & $\mathbf{1 2 1}$ & $\mathbf{1 0 0 . 0}$ \\
\hline
\end{tabular}


Table 3. Preferable SSA Countries for Visits

\begin{tabular}{|c|c|c|}
\hline SSA Region and Countries & Frequency & Percentage \\
\hline \multicolumn{3}{|l|}{ Southern Africa Region } \\
\hline South Africa & 25 & 20.7 \\
\hline Namibia & 15 & 12.4 \\
\hline Botswana & 8 & 6.6 \\
\hline Zimbabwe & 8 & 6.6 \\
\hline Lesotho & 4 & $3 \cdot 3$ \\
\hline Malawi & 2 & 1.7 \\
\hline Zambia & 2 & 1.7 \\
\hline Mozambique & 1 & 0.8 \\
\hline \multicolumn{3}{|l|}{ Eastern Africa Region } \\
\hline Tanzania & 13 & 10.7 \\
\hline Kenya & 11 & 9.1 \\
\hline Uganda & 7 & 5.8 \\
\hline Ethiopia & 4 & 3.3 \\
\hline Rwanda & 2 & 1.7 \\
\hline \multicolumn{3}{|l|}{ Western Africa Region } \\
\hline Ghana & 7 & 5.8 \\
\hline Senegal & 1 & 0.8 \\
\hline Cameroon & 1 & 0.8 \\
\hline Cote d'Ivoire & 1 & 0.8 \\
\hline Togo & 1 & 0.8 \\
\hline Benin & 1 & 0.8 \\
\hline Guinea & 1 & 0.8 \\
\hline \multicolumn{3}{|l|}{ Islands } \\
\hline Comoros & 3 & 2.5 \\
\hline Seychelles & 3 & 2.5 \\
\hline Total & 121 & 100 \\
\hline
\end{tabular}

Table 4. Image of tourism product in general in SSA

\begin{tabular}{|c|c|c|}
\hline Measurement Item & Mean & Std. Deviation \\
\hline its products offer value for money & 3.42 & 1.031 \\
\hline it is safe and secure to visit & 3.23 & 0.846 \\
\hline it offers quality service & 3.44 & 0.982 \\
\hline it can be easily reached/accessed & $\mathbf{3 . 0 2}$ & $\mathbf{0 . 8 9 4}$ \\
\hline its information is easy to obtain & 3.24 & 0.875 \\
\hline it has unspoiled nature & $\mathbf{4 . 3 6}$ & $\mathbf{0 . 8 7 4}$ \\
\hline It has authentic culture & $\mathbf{4 . 3 7}$ & $\mathbf{0 . 9 1 4}$ \\
\hline $\begin{array}{c}\text { It has plenty of historic sites and monuments, } \\
\text { including German monuments in Africa }\end{array}$ & 3.32 & $\mathbf{1 . 0 0 8}$ \\
\hline Overall & $\mathbf{3 . 6 7}$ & $\mathbf{0 . 9 2 8}$ \\
\hline
\end{tabular}

Table 5. Wish to participate in CBT when visiting SSA in future

\begin{tabular}{|c|c|c|}
\hline Wish to Participate in CBT & & \\
\hline Maybe & 23 & 19.0 \\
\hline Yes & 98 & 81.0 \\
\hline Total & $\mathbf{1 2 1}$ & $\mathbf{1 0 0 . 0}$ \\
\hline
\end{tabular}

In order to explore motivation behind choice of SSA CBT, respondents were requested to rate the importance ( $1=$ "Not important at all" to $5=$ "Very Important") of various motivations in influencing their wish to choose SSA CBTs as part of their holiday. 
Table 6 indicates that push factors such as "interacting with local communities" (mean statistics of 4.26, standard deviation of 0.801 ) and "learning new things from local communities like preparing traditional foods/drinks, traditional knowledge and practices" (mean statistics of 4.21, standard deviation of 0.763 ) were the most important, followed by "giving back to local communities, contributing something directly to them" (mean statistics of 4.12, Standard Deviation of 0.905). On the other hand, pull factors such as "local fauna and flora, and their traditional uses" (mean statistics of 4.45, standard deviation of 0.806 ) and "history and heritage of local communities" (mean statistics of 4.18, standard deviation of 0.707 ) were the most important motivations, followed by "non-touristy neighborhood" (mean statistics of 4.05, Standard Deviation of 0.999). In addition, while the opportunity for "volunteering in local community activities such as in schools, clinics and orphanage centers" was a less important motivation (mean statistics of 2.91, Standard Deviation of 1.118), the need for "relaxing and entertained by local community through local festivals and entertainments" was rated as fairly important (mean statistics of 3.84, Standard Deviation of 0.919).

Table 6. The importance of different factors in influencing participation in community-based tourism in sub-Sahara Africa

\begin{tabular}{|c|c|c|}
\hline & Mean & Std. Deviation \\
\hline interacting with local communities & $\mathbf{4 . 2 6}$ & $\mathbf{0 . 8 0 1}$ \\
\hline $\begin{array}{c}\text { learning new things from local communities like preparing traditional } \\
\text { foods/drinks, traditional knowledge and practices etc. }\end{array}$ & 4.21 & 0.763 \\
\hline $\begin{array}{c}\text { experiencing traditional activities such as healing, rituals, making of } \\
\text { traditional huts and vernacular architecture }\end{array}$ & 3.88 & 1.002 \\
\hline volunteering in local community e.g schools, clinics, orphanage centres & $\mathbf{2 . 9 1}$ & $\mathbf{1 . 1 1 8}$ \\
\hline giving back to local communities, contributing something directly to them & 4.12 & 0.905 \\
\hline staying longer with communities for in-depth experience of their daily life & 3.75 & 0.933 \\
\hline Relaxing and entertained by local community e.g. festivals, entertainment & 3.85 & 0.919 \\
\hline local fauna and flora, and their traditional uses & $\mathbf{4 . 4 5}$ & $\mathbf{0 . 8 0 6}$ \\
\hline history and heritage of local communities & 4.18 & 0.707 \\
\hline non-touristy neighborhood & 4.03 & 0.999 \\
\hline
\end{tabular}

An open-ended question was asked to respondents in order to obtain more insights regarding motivations behind their choice of SSA CBT. Table 7 shows the key responses. Some respondents mentioned that "meeting and interacting with local people is the best way to discover and know a country better". CBT offers opportunities to meet local people and satisfy tourists' desire to know better and discover a country. Motives such as "to ask for advice from local people regarding what to see and discover in the community, like local hidden objects such as gems" were mentioned by some respondents.

This means that some potential tourists believe that the local community holds some experience that they would otherwise not get if not engaged in CBTs. They would thus wish to engage in an experience of discovery about communities and their beliefs. Other reported reasons include "visiting local religious places", "having unique experience like seeing different things", "spending a few nights with local communities", "getting deeper into local culture", "getting in touch with people behind the normal scenery of landscape and wildlife, what routines and rituals they have and how their day-to-day life looks like", and "to know point of views of local communities".

They also include "to learn and know local cultures and traditions including traditional rituals and wisdom, cuisine (food preparation and tasting). With respect to learning some potential tourists consider their interaction with the local communities as mutual exchange where they also learn by talking to the local people. 
Table 7. Responses to open-ended question regarding reasons for choosing SSA CBT

\begin{tabular}{|c|c|}
\hline Themes & Verbatim \\
\hline $\begin{array}{l}\text { To Meet friends and } \\
\text { relatives and families }\end{array}$ & $\begin{array}{l}\text {...a friend of mine whom we want to visit in Tanzania works in communities... } \\
\text {...I would like to get in contact with young families out there... }\end{array}$ \\
\hline To Discover a country & $\begin{array}{l}\text { "Because it is the best way to discover a country" } \\
\text { "the most interesting part of a country is its people" } \\
\text { "To get to know the Country and the people better." }\end{array}$ \\
\hline To get into local culture & $\begin{array}{l}\text { "yes, because I think it is important to get into local culture and to } \\
\text { get to know local people" }\end{array}$ \\
\hline $\begin{array}{l}\text { Mutual exchange and } \\
\text { Interaction }\end{array}$ & $\begin{array}{l}\text { "Yes, if it is a mutual exchange" } \\
\text { "exchange ideas" } \\
\text { "engaging with the local culture is always one of my strongest } \\
\text { motivations for travelling" } \\
\text { "to talk to the local people" } \\
\text { "If I just want to see mountains and elephants, I can watch a BBC } \\
\text { documentary. The real experience begins with interaction" }\end{array}$ \\
\hline $\begin{array}{l}\text { Authentic/real local } \\
\text { experience }\end{array}$ & $\begin{array}{l}\text { "...get in touch with local people in real world..." } \\
\text { "Get to know culture and the authentic local life" } \\
\text { "would like to experience the real Africa away from the big cities" } \\
\text { "it's part of having a genuine local experience," }\end{array}$ \\
\hline To learn local traditions & $\begin{array}{l}\text { "I am very interested to learn more about local traditions" } \\
\text { "To be able to celebrates and respects traditional cultures, rituals and wisdom." }\end{array}$ \\
\hline Local food experience & “Culinary", "I would love to engage in, for example, cooking" \\
\hline $\begin{array}{l}\text { To know/learn local } \\
\text { culture and society }\end{array}$ & $\begin{array}{l}\text { "Getting to know the local culture is important for me" } \\
\text { "I would like to meet nicepeople and engage in conversation or learn something, } \\
\text { for example a cooking course, but also learn about politics and society" } \\
\text { "It is interesting to try to see how people live in other countries" }\end{array}$ \\
\hline $\begin{array}{l}\text { To discover lo } \\
\text { hidden object }\end{array}$ & "asking for advice what to see especially hidden gems" \\
\hline Religious & "visits \\
\hline $\begin{array}{l}\text { Spend somed } \\
\text { local commun }\end{array}$ & "spend a few nights there with local communities" \\
\hline Have unique $\mathrm{e}$ & “...and have a unique experience", “...in order to see different things" \\
\hline $\begin{array}{l}\text { Getting deeper } \\
\text { into local culture }\end{array}$ & $\begin{array}{l}\text { "I like to get deeper into the culture(s), to get in touch with people } \\
\text { behind the normal "Scenery" (beautiful landscape and Wildlife } \\
\text { Safaris)"... "see how they live, what routines and rituals they have } \\
\text { and how their day-to-day live looks like, how they feel etc" }\end{array}$ \\
\hline $\begin{array}{l}\text { Its most interesting } \\
\text { part of holiday }\end{array}$ & "I think that would be the most interesting part of a holiday" \\
\hline $\begin{array}{l}\text { Be integrated in } \\
\text { the community }\end{array}$ & "I would like to feel myself integrated in the community" \\
\hline To know local point of view & $\begin{array}{l}\text { "I would like to know more About their way of handling Things, } \\
\text { their point of view" }\end{array}$ \\
\hline $\begin{array}{l}\text { To contribute to } \\
\text { community }\end{array}$ & $\begin{array}{l}\text { "But the people who offer such opportunities should really profit } \\
\text { from it themselves. And I don't want to be a part of postcolonial } \\
\text { tourism, where communities are reduced to their "traditional" lifestyle, } \\
\text { only to satisfy white tourists and give them "authentic" experiences" } \\
\text { "I would like to support local communities through tourism" } \\
\text { "means of empowerment for communities (but it has to be done right)" }\end{array}$ \\
\hline & typical ghetto-situations like in big hotels" \\
\hline
\end{tabular}

Another notable response was that of "to avoid ghetto-situations" and viewing CBTs as a means to avoid ghetto/touristic-situations "like in big hotels and towns and 
cities”. Some potential tourists consider CBT offers authentic or real local experience, and that they will be able to get in touch with the real world of local communities, and experience 'the real and genuine Africa away' which is seen as away from big cities and designated parks. Typical responses included the following:

"If I just want to see mountains and elephants, I can watch a BBC documentary. The real experience begins with interaction".

"Well, in previous holidays, I had several of these kinds of encounters/chances to meet people like that and it was most rewarding. However, I personally make a distinction between ordinary "holiday", where I do not have so much time i.e. 2-3 weeks. In this case, the engagement can only be brief (1-3 days) in order to see different things. The other possibility for me personally is more like a "vacation/journey", where I have more time on my handy (more than 4 weeks). Then, a longer engagement is brilliant".

"I would like to meet nice people and engage in conversation or learn something, for example a cooking course, but also learn about politics and society. But the people who offer such opportunities should really profit from it themselves. And I don't want to be a part of postcolonial tourism, where communities are reduced to their "traditional" lifestyle, only to satisfy white tourists and give them "authentic" experiences".

Respondents who were unsure regarding their choice to visit SSA CBT if given a chance also responded to the open-ended question inquiring the reasons. Responses include "I do not want to interfere with their (local community) daily life" ... "I do not want to be a nuisance". "I think time would be too short to really have an impact" ... "I would love to do that, but it needs be organized in a professional way" ... "safety in terms of diseases". In addition, other responses include "infections", "crimes", and "flying to Africa increases my carbon footprint way beyond my global share". Such results strengthen earlier findings (Table 4) about poor image regarding safety and security, and quality of services reflected with the need for professionally - delivered CBT products are among critical problems that tarnish the image of SSA's tourism. They also add that potential tourists' concerns to sustainability matters such as socio-cultural interference and environmental pollution they might cause when visiting SSA CBTs possibly can affect their choices.

\section{Source of information and Travel arrangements}

The study, as part of demand analysis, asked respondents about the means through which they receive information on SSA CBTs. As indicated in Table 8, a segment of respondents (15.7\%) percent had never heard or aware about SSA CBT products.

For the remainder the internet and websites (34.7\%), word-of-mouth (26.4\%) were the most popular sources for information. Other sources include tourism publications such as guide books, brochure and travel magazine (9.9\%), mass media (5.8\%) and education institutions (5\%). Travel agents in Germany (1.7\%) and fairs and exhibitions (o.8\%) were the least significant sources of information.

Table 8. Sources of information about SSA CBTs

\begin{tabular}{|l|c|c|}
\hline & Frequency & Percent \\
\hline Ihave never heard or learnt about community-based tourism products of sub-Sahara Africa & 19 & 15.7 \\
\hline Internet and websites & 42 & 34.7 \\
\hline Tourism publications such as guide books, brochure, travel magazine & 12 & 9.9 \\
\hline Travel agents in Germany & 2 & 1.7 \\
\hline Word of mouth - family members, and friends and relatives & 32 & 26.4 \\
\hline Fairs and exhibitions & 1 & 0.8 \\
\hline Schools, colleges and universities & 6 & 5.0 \\
\hline Mass media such as television and radio stations, and newspapers & 7 & 5.8 \\
\hline \multicolumn{1}{|c|}{ Total } & $\mathbf{1 2 1}$ & $\mathbf{1 0 0 . 0}$ \\
\hline
\end{tabular}


In order to understand CBT demand respondents were asked about modalities in which they would wish to arrange their travel to SSA CBT destinations. Several modalities from past literature were considered. Results as shown in Table 9 indicate that the majority (75.3 percent) would wish to arrange the tour themselves ie an individual arrangement. This includes individual arrangement via direct contact with destinations and product providers, via mainstream online booking channels and travel search engines or combining direct contact with product providers and mainstream online booking channels and travel search engines. Almost a quarter of respondents prefer an intermediary, such as tour operators or travel agents, arrange their travel to SSA CBT. A small number would use both intermediaries and individual arrangements, including using friends and relatives who are in SSA (Table 9).

Table 9. SSA CBT tour arrangement

\begin{tabular}{|c|c|c|}
\hline & Frequency & Percent \\
\hline $\begin{array}{l}\text { Arrange the tour myself (individual arrangement) via direct contact with } \\
\text { destinations and product providers in sub-Sahara Africa }\end{array}$ & 44 & 36.4 \\
\hline $\begin{array}{l}\text { Arrange the tour myself (individual arrangement) via direct contact with destinations } \\
\text { and product providers in sub-Sahara Africa, friends who have contacts there }\end{array}$ & 3 & 2.5 \\
\hline $\begin{array}{l}\text { Arrange the tour myself (individual arrangement) via mainstream online } \\
\text { booking channels and travel search engines }\end{array}$ & 23 & 19.0 \\
\hline $\begin{array}{l}\text { Arrange the tour myself (individual arrangement) via mainstream online booking } \\
\text { channels and travel search engines, Arrange the tour myself (individual arrangement) } \\
\text { via direct contact with destinations and product providers in sub-Sahara Africa }\end{array}$ & 18 & 14.9 \\
\hline $\begin{array}{l}\text { Arrange the tour myself (individual arrangement) via mainstream online } \\
\text { booking channels and travel search engines, Arrange the tour myself } \\
\text { (individual arrangement) via direct contact with destinations and product } \\
\text { providers in sub-Sahara Africa, a mix of the last two options }\end{array}$ & 3 & 2.5 \\
\hline $\begin{array}{l}\text { If it is the first time, I'd have it arranged by tour operators; if not, I'd get in } \\
\text { contact with providers in sub-Sahara Africa }\end{array}$ & 1 & .8 \\
\hline Maybe organized-tour arranged by a local community operator. & 1 & .8 \\
\hline $\begin{array}{l}\text { mix of those, an organized tour by tour operator, that works only with local } \\
\text { providers, so that benefits stay at the destination }\end{array}$ & 3 & 2.5 \\
\hline Organized-tour arranged by tour operators/travel agents & 13 & 10.7 \\
\hline $\begin{array}{l}\text { Organized-tour arranged by tour operators/travel agents, Arrange the tour } \\
\text { myself (individual arrangement) via direct contact with destinations and } \\
\text { product providers in sub-Sahara Africa }\end{array}$ & 1 & .8 \\
\hline $\begin{array}{l}\text { Organized-tour arranged by tour operators/travel agents, Arrange the tour } \\
\text { myself (individual arrangement) via mainstream online booking channels and } \\
\text { travel search engines }\end{array}$ & 4 & $3 \cdot 3$ \\
\hline $\begin{array}{l}\text { Organized-tour arranged by tour operators/travel agents, Arrange the tour myself } \\
\text { (individual arrangement) via mainstream online booking channels and travel } \\
\text { search engines, Arrange the tour myself (individual arrangement) via direct } \\
\text { contact with destinations and product providers in sub-Sahara Africa }\end{array}$ & 3 & 2.5 \\
\hline $\begin{array}{l}\text { Organized-tour arranged by tour operators/travel agents, Arrange the tour myself } \\
\text { (individual arrangement) via mainstream online booking channels and travel } \\
\text { search engines, Mixture between organized tours and individual arrangement }\end{array}$ & 1 & .8 \\
\hline $\begin{array}{l}\text { Organized-tour arranged by tour operators/travel agents, to be organized by a } \\
\text { local friend/relative }\end{array}$ & 3 & 2.5 \\
\hline Total & 121 & 100.0 \\
\hline
\end{tabular}

\section{DISCUSSION}

Overall, the findings of this study disclose a considerable potential demand for SSA tourism in general, and for CBT in particular and most especially for South Africa, 
Tanzania and Namibia. This demand corresponds to potential tourists who would wish to meet and interact with local communities, to experience their lifestyle and traditions, and stay longer with the local community in order better to understand the way people live. Apart from the interaction-based push factor, the findings reveal cultural motives such as novelty, authenticity and gaining new knowledge, especially learning new things from local communities such as preparing traditional foods/drinks, traditional knowledge and practices, sharing economy ethos and issues such as relaxation are important influences. Interaction is expressed by some respondents as the best way to discover and know a country better. Accordingly, CBTs are thought to offer opportunities to meet local people of a country and thus satisfy tourist desires to not only socialize, but also to know better and discover a country "knowledge". The analysis shows that interaction and knowledge/education appeared the most important push factors for CBT.

The study also reveals that potential tourists would wish to go beyond the normal common scenes and 'get deeper' into a community's culture. Qualitative statements such as "getting in touch with people behind the normal scenery of landscape and wildlife, what routines and rituals they have and how their day-to-day life looks like", and "to know point of views of local communities" express the desire to have unfamiliar and novel experiences that enhance individual's knowledge. Statements such as "to avoid ghetto-situations" signal a desire for authentic local experiences rather than traditional touristic settings such as at hotels or lodges. This implies some potential tourists consider CBT for authentic or real local experience. Such results suggest that CBT planners and managers should design products to satisfy multiple motives including interaction, knowledge/education, novelty and authenticity. To foster interaction, communication is a key, and thus having local communities or guides who can communicate effectively with tourists is critical. Local communities should be set to interact with the tourists in a meaningful and mutually beneficial way. This is where CBT product elements such as home stays, cultural centers and storytelling can be useful. The interaction modality should be accompanied by effective interpretation strategies which can be used to foster knowledge/education.

New (or perhaps interesting) local stories and legends, as well as locally blended tourist facilities like homestays can aid into fostering novelty and authentic experience. In common with other research, the findings in this study reveals the desire to volunteer in local "other" community activities such as schools, clinics and orphanage centers was a less important motivation (Table 6). In this research, relaxation was a fairly important motive behind visits to CBT in Africa combined with relaxation experiences in dominant forms of tourism in Africa such as beach and safari visits. Tourists traveling with the core reason of relaxation would rarely set time aside for volunteering. Regarding CBT, interaction, learning, novelty and authentic experiences, rather than engagement in volunteering in terms of working in the community, may form part of relaxation experience. Arguably, the volunteer motive is expressed in another way, especially with potential tourists' desire to share economy ethos such as desires to give to "other" communities and contributing something directly to them. Accordingly, the item "giving back to local communities, contributing something directly to them" is an important motive for deciding to visit CBT.

Overall, regarding push motives, the study indicates that interaction is the most important motive. This finding corroborates results by Guttentag et al. (2018) and Agyeiwaah (2013). Multiple motives that involve interaction, a mix of cultural motives, altruistic with some levels of physical relaxation imply that motives behind choice of CBT probably extend beyond dichotomous polarized discourses of hard versus soft as contended by CBI (2015). Indeed, this research reveals the plurality of potential tourist demand for CBT in Africa and its broader outline dominated by interaction as the most important push motive. Potential tourists to SSA can be attracted by pull factors 
including local fauna and flora, but in the CBT context are more concerned about their traditional uses, and history and heritage of local communities. With respect to the tourism product in general in SSA, the research highlights potential tourists hold a good image regarding the region's tourism product in terms of its authentic culture and unspoiled nature. Natural and cultural attractions that translate into tourist activities at the destination dominate as pull factors, a finding that reflects other studies (see Jang \& $\mathrm{Wu}, 2006$; Isa \& Ramli, 2014). This said, the findings reveal that what pulls tourists to CBTs in particular is not only the object authenticity of African cultural and natural attractions but also their traditional uses by the communities. While nature including flora and fauna and its scenery are dominant pull factors among general tourists to Africa, their cultural and functional dimensions in terms of community uses, are primary pull factors among CBT tourists. Arguably, while culture, heritage and history are secondary interests to general tourists to Africa (Kline et al., 2014; Sidali \& Schulz, 2010) they are primary to potential CBT tourists, who often combine CBT with other attractions. CBT managers should strive therefore not only to showcase community's flora and fauna and natural scenery, but also to portray their functional dimensions, including their historic and cultural values as well as traditional and contemporary uses by local communities. This would portray differences between tourist's experience of nature-based tourism and experience of CBT, and thus justify visits to CBT products.

The results in this study also demonstrate that conventional factors such as accessibility including transport and infrastructure, safety and security, and value for money (quality of services) are important for tourists in deciding to visit CBTs. Several qualitative responses included "crime" and "infections" were expressed by respondents who were unsure whether they would wish to visit CBT. This strengthen the argument that potential tourists' perception of security (peace) and safety including cleanliness and hygiene of facilities (such as toilets, showers, accommodation and kitchens) at the destination are among critical considerations in decisions to visit SSA CBTs. In addition, there is a general concern over the quality of service provided by CBTs, implying that providers of services (e.g. tour guides, home stays, cooks, waiters and waitresses) need to ensure professionalism, cleanliness and hygiene, and comfort in their delivery of service. In addition, the research found that the factor German spoken at the destination is important for potential tourists to decide to visit CBT. Interaction is key for experiencing CBTs, and thus communication and access to information through German-speaking tour guides, interpreters and information/interpretation labels with multiple languages are critical in ensuring successful interaction. Findings in this study indicate there is a segment of respondents that are unsure if given the chance that they would visit SSA CBTs. Concerns were highlighted over sustainability elements, especially interference they may cause to socio-cultural and environmental components of the communities, and time available to visit the CBTs. Potential tourists are concerned with the fact that their visit to CBT would interfere communities and may end up being nuisance to local communities. Others expressed concerns about their impacts in environmental pollution especially to remote and rural areas of African communities. Finally, responses indicate that potential tourists are concerned with time factor in their choice to visit CBT in future. They perceive that much time is needed to engage and interact with the local community to satisfy their experience. Of course, it is well known from the past literature that, while experiencing culture often demands substantial amounts of time, tourists travel on finite time budget to capture multiple experiences that they would desire (McKercher et al., 2002).

With reference to distance decay theory (McKercher et al., 2002) demand for CBT products varies inversely with distance traveled which reflects tourists' consideration of time spent to reach the attractions. This suggests that demand for CBT would probably 
decline exponentially as time (distance) required increase, with a reservation that most tourists to SSA are traditionally and primarily attracted by warm climate, beach and the wilderness. The implication of this finding is that, the proximity of CBT products to gateways and major tourism iconic destinations like national parks, or on the other hand, the presence of transport facilities such as air transport that can quickly and reliably connect between iconic destinations and CBT products may probably influence their potential visitation. Overall, regarding CBT tourist pull factors, while attractions, accessibility, services and facilities and their attributes like quality (value for money), safety and security and professionalism appear well in past CBT research (Wang, 2007; Hsu \& Lin, 2011; Koppalova, 2014; Mtapuri et al., 2015; ADAC Reise-Monitor, 2016), the sustainability and time factors rarely appears in literature. Arguably, to pull tourist, CBTs should not only focus on promoting natural and cultural heritage attractions, address access, services, facilities, quality and professionalism, but should also promote their sustainability concerns and time-effective experiences. This implies that CBT products can portray consumptiontime effective by utilizing its multiple activities to deliver multiple complementary experiences. This will make tourists, especially those who visit SSA primarily for other experiences than CBT, to find a justification for visiting CBTs. In terms of information access the findings point to the internet and websites, word-of-mouth and tourism publications as the most common means through which potential tourists get information about SSA CBT. Such findings indicate that mainstream online booking channels and travel search engines are important means through which potential tourists can individually arrange their travel, others being direct contact with destinations and product providers, and friends and relatives who are in SSA. It is evident that potential tourists prefer individual arrangements than intermediaries and use multiple sources for information.

\section{CONCLUSIONS}

Several studies report the relatively poor economic performance of CBTs (Mitchell \& Muckosy, 2008; Goodwin \& Santilli, 2009). The limited empirical information regarding potential market demand and its motives make it challenging for CBTs to attract sufficient numbers of tourists in order to be financially sustainable. It is against this backdrop that the research explored potential demand and motives for SSA CBT based on potential German tourists in their pre-visit stage. It is evident based on the empirical findings that potential international tourists for a traditionally nature-based destination - the SSA - have a desire to visit the local communities as part of their holiday travels. There is thus a considerable opportunity for SSA CBTs. It was shown that interaction is the major push motive for choosing to visit CBT products. This is different from motives behind conventional nature-based tourism where the physical factor related to relaxation and excitement is the major motive. This said, relaxation in terms of having fun and being entertained by local community is part of important motives for choosing CBTs the others are search for novel, authentic and education experiences. Overall, the research findings argue for the plurality of motives behind the choice to visit CBTs.

This result contrasts with the conventional argument that the push motives represent the dichotomous polarized discourses of soft versus hard with reference to the notion of relaxation - the former involving relaxation as key motive while the latter involving authenticity-seeking as central motive. The dichotomous polarized argument understates the plurality of people's motives and choices that this study reveals. For CBT managers and policy makers this implies that motives behind demand for CBT products are complex and not confined simply to either hard or soft desires. It means that while efforts must be made to provide opportunities for deep interaction and for educative, novel and authentic experiences CBT managers should not overlook opportunities for 
satisfying the sharing economic ethos as well as the imperative to ensure a relaxing comfortable experience. Regarding this, relaxation should be complementary part of the CBT experience so as to not overload visitors with too much interaction and intentional learning. The consideration of a sample of potential tourists in their pre-visit, a stage where their desires are not affected by on-travel experiences and interactions, has revealed important issues regarding demand for CBTs. However, due to the small sample size and market confined to a single German locality around Eberswalde, mostly people associated with the university (students and staff) - a university that is committed to sustainable development - and with relatively advantaged potential for travelling abroad, the results can be used as a basic framework for further studies. The study considered a sample of residents in their pre-visit stage in Germany as an origin region. The results might be viewed as biased to the extent that the influence of the on-travel experiences and interactions that tourists would have on their wishes and desire for CBT are not reflected here. Nevertheless, by not considering on-travel effects this study broadens our understanding of tourists' decision-making process of choosing to visit a place based on pre-visit perceptions which can be more genuine and intrinsic motives than motives changes occurring on-travel. In future, the knowledge base about international demand for CBT products can build upon this exploratory study more particularly by the pursuit of larger-scale investigations.

\section{Acknowledgement}

This research was undertaken as a 2018 TWAS Visiting Scientist, Centre for Sustainable Tourism, Eberswalde University of Sustainable Development, Germany. I acknowledge the mentorship Prof. Wolfgang Strasdas (Eberswalde University of Sustainable Development) as well as inputs from students of HNEE Centre for Sustainable Tourism (Eberswalde University of Sustainable Development). Comments from two anonymous reviewers and editorial assistance from Chris Rogerson are appreciated for revision of the paper. The World Academy of Science (TWAS) and University of Johannesburg are thanked for funding.

\section{REFERENCES}

Agyeiwaah, E. (2013). International Tourists' Motivations for Choosing Homestay in the Kumasi Metropolis of Ghana. Anatolia: An International Journal of Tourism and Hospitality Research, 24 (3), 405-409.

Akunaay, M., Nelson, F. \& Singleton, E. (2003). Community-based Tourism in Tanzania: Potential and Perils in Practice. Paper presented at the Second IIPT Africa Conference on Peace through Tourism, Community Tourism - Gateway to Poverty Reduction, Dar es Salaam.

Anderson, W. (2015). Cultural Tourism and Poverty Alleviation in Rural Kilimanjaro, Tanzania. Journal of Tourism and Cultural Change, 13 (3), 208-224.

Atanga, R. (2019). Stakeholder Views on Sustainable Community-Based Ecotourism: A Case of The Paga Crocodile Ponds, Ghana. GeoJournal of Tourism and Geosites, 25 (2), 321-333.

Choi, W.M. \& Tsang, C.K.L. (2000). Activity-based Segmentation on Pleasure Travel Market of Hong Kong Private Housing Residents. Journal of Travel and Tourism Marketing, 8 (2), 75-97.

Creswell, J.W. (2003). Research Design: Qualitative, Quantitative, and Mixed Methods Approaches. London: SAGE.

Croes, R. (2014). The Role of Tourism in Poverty Reduction: An Empirical Assessment. Tourism Economics, 20 (2), $207-226$.

Crompton, J. L. (1979). Motivations of Pleasure Travel. Annals of Tourism Research, 6, 408-424.

Dodds, R., Ali, A. \& Galaski K. (2018). Mobilizing Knowledge: Determining Key Elements for Success and Pitfalls in Developing Community-based Tourism. Current Issues in Tourism, 21 (13), 1547-1568.

Eusébio, C., Carneiro, M.J., Kastenholz, E., Figueiredo, E. \& da Silva, D.S. (2017). Who is Consuming the Countryside? An Activity-based Segmentation Analysis of the Domestic Rural Tourism Market in Portugal. Journal of Hospitality and Tourism Management, 31, 197-210.

Goeldner, C.R. \& Ritchie, J.R.B. (2006) Tourism: Principles, Practices and Philosophies. New Jersey: John Wiley (10 $10^{\text {th }}$ Ed.).

Goodwin, H. \& Santilli, R. (2009). Community-based Tourism: A Success. Leeds: ICRT Occasional Paper No. 11.

Guttentag, D., Smith, S., Potwarka, L. \& Havitz, M. (2017). Why Tourists Choose Airbnb: A Motivation-based Segmentation Study. Journal of Travel Research, 57 (3), 342-359. 
Hall, C.M. (2010). Changing Paradigms and Global Change: From Sustainable to Steady-state Tourism. Tourism Recreation Research, 35 (2), 131-145.

Hitchins, R. \& Highstead, J. (2005). Community-based Tourism in Namibia. Johannesburg: ComMark Trust.

Hsu, S.L. \& Lin, Y.M. (2011). Factors Underlying College Students' Choice of Homestay Accommodation while Travelling. World Transaction on Engineering and Technology Education, 9 (3), 196-202.

Huang, W.J., Beeco, J.A., Hallo, J.C. \& Norman, W.C. (2016). Bundling Attractions for Rural Tourism Development. Journal of Sustainable Tourism, 24 (10), $1387-1402$.

Iso-Ahola, S. (1982). Towards a Social Psychology Theory of Tourist Motivation. Annals of Tourism Research, 9, $256-262$.

Jang, S. \& Wu, C.M.E. (2006). Seniors' Travel Motivation and the Influential Factors: An Examination of Taiwanese Seniors. Tourism Management, 27, 306-316.

Kayat, K. (2014). Community-based Rural Tourism: A Proposed Sustainability Framework. SHS Web of Conferences, 12,1 -7.

Klenosky, D.B., LeBlanc, C.I., Vogt, C.A. \& Schroeder, H.W. (2007). Factors That Attract and Repel Visitation to Urban Recreation Sites: A Framework for Research, North-Eastern Recreation Research Symposium, 39-45.

Kline, C.S., Greenwood, J.B., Swanson, J. \& Cardenas, D. (2014). Paddler Market Segments: Expanding Experience Use History Segmentation. Journal of Destination Marketing and Management, 2, 228-240.

Kontogeorgopoulos, N., Churyen, A. \& Duangsaeng, V. (2014). Success Factors in Community-Based tourism in Thailand: The Role of Luck, External Support and Local Leadership, Tourism Planning and Development, 11 (1), 106 - 124.

Koppalova, N. (2014). German market analysis: Tourist behavior research. Unpublished Bachelor Thesis, MAMK, Germany.

Lapeyre, R. (2010). Community-based tourism as a sustainable solution to maximize impacts locally? The Tsiseb Conservancy case, Namibia. Development Southern Africa, 27 (5), 757-772.

López-Guzmán, T., Sanchez, S. \& Pavon, V. (2011). Community-based Tourism in Developing Countries: A Case Study, Tourismos: An International Multidisciplinary Journal of Tourism, 6 (1), 69-84.

Lubbe, B.A., Douglas, A., Fairer-Wessels, F., Kruger, E. \& Geldenhuys, E. (2016). Matching Tourism Supply and Demand: An Analysis of How Tourism Products Meet the Needs of Emerging Domestic Market Segments in Selected Regions in South Africa. Tourism, Travel and Research Association (TTRA), Advancing Tourism Research Globally, 25. http://scholarworks/umass.edu/ttra/2013/Academic PapersOral/25

Lwoga, N.B. (2011). Tourism: Meaning, Practices and History. Dar es Salaam: Dar es Salaam University Press.

Lwoga, N.B. \& Asubisye, E. (2016). Effects of Drought on Cultural Tourism: Selected Cases of Maasai Tourism Groups Surrounding Tarangire National Park in Tanzania. Journal of Tourism and Cultural Change, 16 (3), 248-264.

Madrigal, R. \& Kahle, L. R. (1994). Predicting Vacation Activity Preferences on the Basis of Value-system Segmentation. Journal of Travel Research, 33 (3), 22-28.

Manyara, G. \& Jones, E. (2007). Community-based Tourism Enterprises Development in Kenya: An exploration of Their Potential as Avenues of Poverty Reduction, Journal of Sustainable Tourism, 15 (6), 628-644.

McKercher, B., Ho, P.S.Y., du Cros, H. \& So-Ming, B.C. (2002). Activities-based Segmentation of the Cultural Tourism Market. Journal of Travel and Tourism Marketing, 12 (1), 23-46.

Mehmetoglu, M. (2007). Topologizing Nature-based Tourists by Activity: Theoretical and Practical Implications. Tourism Management, 28, 651-660.

Mgonja, J.T., Sirima, A., Backman, K. F. \& Backman, S. J. (2015). Cultural Community-based Tourism in Tanzania: Lessons Learned and Way Forward. Development Southern Africa, 32 (3), 377-391.

Mitchell, J. \& Ashley, C. (2007). Pathways to Prosperity - How Can Tourism Reduce Poverty: A Review of Pathways, Evidence and Methods. Washington, DC: World Bank.

Mitchell, J. \& Muckosy, P. (2008). A Misguided Quest: Community-based Tourism in Latin America. London: Overseas Development Institute. Opinion 102.

Mowforth, M. \& Munt, I. (2003). Tourism and Sustainability: Development and New Tourism in the Third World. London: Routledge.

Mtapuri, O., Giampiccoli, A. \& Jugmohan, S. (2015). Community-based Tourism Affinity Index: A Visitor's Approach, African Journal of Hospitality, Tourism and Leisure, 4 (2), 1-13.

Mumuni, A.G. \& Mansour, M. (2014). Activity-based segmentation of the outbound leisure tourism market of Saudi Arabia, Journal of Vacation Marketing, 20 (3), 239-252.

Murphy, P.E. (1985). Tourism: A Community Approach. New York: Methuen.

Nyaupane, G.P., White, D. \& Budruk, M. (2006). Motive-based Tourist Market Segmentation: An Application to Native American Cultural Heritage Sites in Arizona, USA. Journal of Heritage Tourism, 1 (2), 81-99.

Park, B., Lee, M. \& Kim, J. (2004). Rural Tourism Market Segmentation. Journal of Tourism Studies, 28 (2), $193-212$.

Park, D.B. \& Yoon, Y.S. (2009). Segmentation by Motivation in Rural Tourism: A Korean Case Study. Tourism Management, 30 (1), 99-108.

Pearce, P. \& Lee, U.L. (2005). Developing the Travel Career Approach to Tourist Motivation. Journal of Travel Research, 43, 226-237.

Perkins, H.C., MacKay, M. \& Espiner, S. (2015). Putting Pinot Alongside Merino in Cromwell District, Central Otago, New Zealand: Rural Amenity and The Making of the Global Countryside. Journal of Rural Studies, 39, 85 - 98.

Pesonen, J. (2012). Segmentation of Rural Tourists: Combining Push and Pull Motivations. Tourism and Hospitality Management, 18 (1), 69 - 82.

Reggers, A., Grabowski, S., Wearing, S.L., Chatterton, P. \& Schweinsberg, S. (2016). Exploring Outcomes of Community-based Tourism on the Kokoda Track, Papua New Guinea: A Longitudinal Study of Participatory Rural Appraisal Techniques. Journal of Sustainable Tourism, 24 (8-9), 1139-1155. 
Rodrigues, C. \& Prideaux, B. (2012). Community-based Tourism in Marajo Island - Brazil. Achieving a Success Story. In: Proceedings. The New Golden Age of Tourism and Hospitality, 6-9 February, Melbourne, Australia.

Rogerson, C.M. (2006). Pro-poor Local Economic Development in South Africa: The Role of Pro-poor Tourism. Local Environment, 11 (1), 37-60.

Rogerson, C.M. (2007). Reviewing Africa in the Global Tourism Economy. Development Southern Africa, 24 (3), $361-379$.

Rogerson, J.M. (2018). The Geography of Tourism Bednights in South Africa. GeoJournal of Tourism and GeoSites, 23 (3), 835-847.

Rogerson, C.M. \& Rogerson, J.M. (2019). Tourism in South Africa's Borderland Regions: A Spatial View. GeoJournal of Tourism and Geosites, 24 (1), 175-188.

Rozemeijer, N. (2001). Community-based Tourism in Botswana: The SNV Experience in Three Communitytourism Projects. Gaborone: SNV Botswana.

Salazar, N.B. (2012). Community-based Cultural Tourism: Issues, Threats and Opportunities. Journal of Sustainable Tourism, 20 (1), 9-22.

Sebele, L.S. (2010). Community-based Tourism Ventures, Benefits and Challenges: Khama Rhino Sanctuary Trust, Central District, Botswana. Tourism Management, 31 (1), 136-146.

Sidali, K. \& Schulz, B. (2010). Current and Future Trends in Consumers' Preference for Farm Tourism in Germany. Leisure/Loisir, 34 (2), 207 - 222.

Sing'ambi, E. \& Lwoga, N.B. (2018). Heritage Attachment and Domestic Tourists' Visits to Historic Sites in Bagamoyo, Tanzania. International Journal of Culture, Tourism and Hospitality, 12 (3), 310-326.

Stone, M.T. \& Rogerson, C.M. (2011).Community-based Natural Resource Management and Tourism: Nata Bird Sanctuary, Botswana. Tourism Review International, 15 (1-2), 159-169.

Strydom, A.J., Mangope, D., \& Henama, U.S. (2019). Making Community-based Tourism Sustainable: Evidence From The Free State Province, South Africa. GeoJournal of Tourism and Geosites, 24 (1), 7-18.

Tashakkori, A. \& Teddlie, C. (1998). Mixed Methodology: Combining Qualitative and Quantitative Approaches. Thousand Oaks, CA: Sage.

Teh, L. \& Cabanban, A.S. (2007). Planning for Sustainable Tourism in Southern Pulau Banggi: An Assessment of Biophysical Conditions and Their Implications for Future Tourism Development. Journal of Environmental Management, 85 (4), 999-1008.

Thompson, C., Johnson, T. \& Hanes, S. (2016). Vulnerability of Fishing Communities Undergoing Gentrification. Journal of Rural Studies, 45, 165-174.

Timothy, D.J. \& Nyaupane, G.P. (2009). Cultural Heritage and Tourism in the Developing World: A Regional Perspective. New York: Routledge.

Wang, C., Qu, H. \& Hsu, M.K. (2016). Toward an Integrated Model of Tourist Expectation Formation and Gender Difference. Tourism Management, 54, 58-71.

Wang, Y. (2007). Customized Authenticity Begins at Home. Annals of Tourism Research, 34 (3), $789-804$.

Zapata, M.J., Hall, C.M., Lindo, P. \& Vanderschaeghe, M. (2011). Can Community-based Tourism Contribute to Development and Poverty Alleviation? Lessons from Nicaragua, Current Issues in Tourism, 14 (8), 725-749.

*** ADAC Reise-Monitor (2016). Trend Research: 2016 Travel Market, Berlin: ADAC Verlag Anzeeigenmarketing

*** CBI (2015). Tailored Intelligence Study - Community-based Tourism (CBT) in Bolivia. Ministry of Foreign Affairs of the Netherlands CBO - Centre for the Promotion of Imports from Developing Countries.

*** EplerWood, M. (1998). Meeting the Global Challenge of Community Participation in Ecotourism: Case Studies and Lesson from Ecuador (Vol. 2). Arlington: The Nature Conservancy.

*** German Consumer and Travel Trade Research (2008). German Consumer and Travel Trade Research Report, Accessed online: https://www.destinationbc.ca/content/uploads/2018/o8/GermanyConsumerTravelTrade Research-sflb.pdf [Accessed 15 November 2018]

*** United Nations World Tourism Organization (UNWTO) (2018). Tourism Highlights 2017 Edition. Madrid: UNWTO.

*** United Republic of Tanzania [URT] (2017). The 2018 Tourism Statistical Bulletin. Dar es Salaam: Ministry of Natural Resources and Tourism, Tourism Division.

*** World Bank (2017). Tourism for Development: 20 reasons Sustainable Tourism Counts for Development. Washington DC: The World Bank Group.

*** World Bank (2019). Africa's Pulse: An Analysis of Issues Shaping Africa's Economic Future. Washington DC: International Bank for Reconstruction and Development/The World Bank.

*** World Tourism Organization (WTO) (2002). Tourism and Poverty Reduction. Madrid: WTO.

*** World Travel \& Tourism Council (WTTC), (2013). Travel and Tourism Economic Impact 2013 Sub Saharan Africa. London, UK: WTTC.

*** World Travel \& Tourism Council (WTTC), (2018). Travel and Tourism Power and Performance Report. London: WTTC.

Submitted:

15.01.2019
Revised:

04.05.2019
Accepted and published online 24.05.2019 